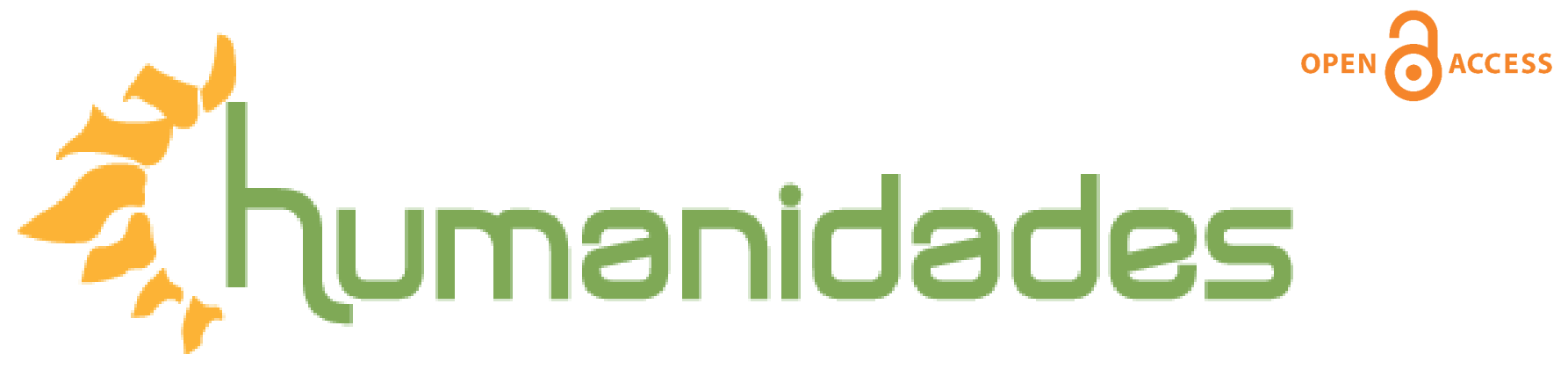

Revista de la Escuela de Estudios Generales, Universidad de Costa Rica

Julio-diciembre, 2018 •Volumen 8, número 2 • EISSN 2215-3934 •pp. 1-21

Recibido: 13-Setiembre-2017 Aceptado:15-Enero-2018

\title{
Reflexiones sobre la persona joven como sujeto social en la legislación costarricense
}

DOI: http://dx.doi.org/10.15517/h.v8i2.33335

\section{Máster Gilbert Ulloa Brenes}

Universidad Estatal a Distancia, Escuela de Ciencias de la Educación, Centro de Investigaciones en Educación. Costa Rica.

Correo electrónico:gilbertodalier@gmail.com

Todos los derechos reservados. Universidad de Costa Rica. Esta revista se encuentra licenciada con Creative Commons. Reconocimiento-NoComercial-SinObraDerivada 3.0 Costa Rica. Correo electrónico: humanidades@ucr.ac.cr / Sitio web: http://revistas.ucr.ac.cr/index.php/ humanidades 


\section{Reflexiones sobre la persona joven como sujeto social en la legislación costarricense}

\section{Resumen}

Como una contribución para el debate alrededor de los procesos de subjetivación de las personas jóvenes en la sociedad costarricense contemporánea, el objetivo de este ensayo consiste en discutir sobre la concepción de persona joven como sujeto social y político en dos documentos oficiales de la legislación nacional: la Ley General de la Persona Joven y la Política Pública de la Persona Joven. Para ello, se construye una aproximación reflexiva a esos textos que, oficialmente, explicitan una forma de reconocimiento oficial de las subjetividades juveniles en Costa Rica, en el marco de una realidad social tributaria de cierta forma de modernidad constitutiva de los sujetos jóvenes.

\section{Reflections on the Young Person as a Social Subject in the Costa Rican Legislation}

\begin{abstract}
As a contribution to the debate around the processes of subjectivation of young people in the contemporary Costa Rican society, the aim of the present essay is to discuss the conception of the young person as a social and political subject in two official documents of the national legislation: Ley General de la Persona Joven (General Law of Young People) and Política Pública de la Persona Joven (Public Policy of Young People). In order to do so, a reflexive approach to these texts is formulated, which formally states a form of official recognition of the youth subjectivities in Costa Rica within the framework of a social reality that is tributary of a certain form of modernity constitutive of young subjects.
\end{abstract}

Palabras claves: Personas jóvenes, subjetividad, Modernidad, sociedad costarricense, legislación.
Keywords: Young people, subjectivity, Modernity, Costa Rican society, legislation. 
Reflexiones sobre la persona joven como sujeto social...

En el estudio de la construcción social de las subjetividades juveniles es oportuno considerar dos procesos convergentes:

\section{Introducción}

-Su emergencia histórica, lo cual implica indagar cómo desde tal aparición las subjetividades juveniles cambian hasta sus aspectos actuales, y -La institucionalización cultural de los discursos y las prácticas que informan sobre tales subjetividades.

Ambos procesos originalmente longitudinales pueden, sin embargo, abordarse por aparte y, en el caso de los discursos y las prácticas institucionalizadas, tratarse de manera transversal.

Empero, esta separación no debería convertirse en una regla si de ofrecer un panorama amplio sobre la constitución de las subjetividades juveniles se trata. Por el contrario, la aspiración por construir conocimientos más allá de las superficies impele a tomar en cuenta ambos flancos de este objeto.

En el plano del devenir histórico, resulta ya un punto de apoyo bastante sólido advertir que, si bien desde siempre han existido personas biológicamente jóvenes, no en todas las épocas históricas su condición subjetiva fue la misma (Souto, 2007).

Por ejemplo, en las sociedades preindustriales de Europa, según apunta Souto (2007), la distinción entre categorías hoy tan aparentemente prístinas como niñez, adolescencia, juventud y adultez no estaba claramente establecida, lo cual no significaba que en ellas no hubiera ciertos discursos y prácticas institucionalizados que atendían y entendían lo "juvenil" de manera particular, sobre todo al interior de las familias y los espacios educativos.

Esto indica que las determinaciones históricas marcan la comprensión, es decir, el sentido cultural que sustenta la existencia de ciertos estadios ontológicos humanos y, por ende, de ciertas categorías sociales definidas por marcadores de edad.

Por ello la juventud como categoría social mejor definida a través de prácticas y discursos específicos, en virtud de los cuales atraviesa los diferentes niveles de la estructura social y de la trama institucional obligando a una consideración de sus particularidades, es de reciente aparición. 
Bien se podría datar su salto a escena hacia finales del siglo XVIII y principios del XIX, con el advenimiento de la Revolución Industrial y la paulatina consolidación de la cultura burguesa, la economía liberal típica del capitalismo decimonónico y la entronización de un discurso adultocéntrico rubricado por estas condiciones históricas; elementos que catalizaron hasta el siglo XX el reconocimiento de los jóvenes como actores sociales.

Este es el criterio de Feixa (2006), para quien el surgimiento de la adolescencia y la juventud como grupos sociales se remonta a los inicios mismos de la Revolución Industrial, siendo hasta en el siglo XX cuando se democratiza la participación de estos grupos al interior de la sociedad.

En el caso de América Latina, Feixa (2006) señala que los discursos de tipo teórico sobre la juventud se remiten a las primeras décadas del siglo $\mathrm{XX}$, con pensadores que entendían esta "[...] como un reservorio moral tanto para la construcción de un 'nuevo' y 'joven' proyecto civilizatorio en la refundación de la nación y la identidad latinoamericana, como para la encarnación de la modernidad 'civil"' (p. 14). A esta fase de reconocimiento de la juventud en América Latina, que el autor llama ensayística-especulativa, seguiría, hacia los sesenta, otra empírico-modernizadora de la mano de las ciencias sociales positivistas y de los institutos de investigación, mientras, en la década de los ochenta, surgió una aproximación de tipo etnográfica-experimental en que predominaban los enfoques sobre las juventudes como bandas o tribus con características propias.

Según ello, Feixa (2006) llama la atención sobre la necesidad de estudiar, actualmente, la juventud desde las metamorfosis que en ella operarían los procesos de la sociedad globalizada y la era digital. Recomendación atinada, ciertamente, pero posible en la medida en que se analice concomitantemente las formas tanto instituidas como alternativas de reconocimiento social de esos cambios y de los sujetos identificados como jóvenes.

De este modo, si históricamente la sociedad Moderna es el marco en que emerge la subjetividad juvenil con las características básicas que se pueden apreciar en ella hoy, cabe preguntar si ¿los sujetos jóvenes, al quedar inscritos como parte de los procesos sociales, culturales, económicos y políticos modernos, aparecerán como ciudadanos legislados desde una cierta visión que los identifica como adultos potenciales, 
Reflexiones sobre la persona joven como sujeto social...

como actores reservados para una futura incorporación a la sociedad según los cánones propios de la adultez?

La moratoria social como forma cultural de reconocimiento de las subjetividades juveniles estaría arraigada, atávica pero quizá bastante sólidamente aún, a las bases mismas de una concepción que en la época de la Revolución industrial ubicaba a niñas y niños, mujeres y jóvenes como parte de una fuerza laboral cuyos requerimientos de paulatina especialización e inserción dentro de la división social del trabajo, impulsó la segmentación de estos sujetos en grupos sociales que participaban de forma diferenciada en la producción y reproducción del sistema en diferentes ámbitos: en el orden de lo doméstico o en las trayectorias escolares, por ejemplo.

Esta dinámica histórica, como se indicaba al principio, converge de manera permanente en ciertos discursos y prácticas que, instituidos de formas específicas en diferentes campos sociales, constituyen en cada época parámetros que perfilan las subjetividades juveniles.

Por ejemplo, hoy la noción de Millennials con que se quiere identificar a un sector de personas jóvenes que, generacionalmente, se considerarían los potenciales adultos que manejarán el mundo, funciona como etiqueta para marcar a individuos que, por su adscripción dentro de ciertos estratos socioeconómicos, son entendidos como jóvenes-adultos con un alto potencial de consumo: "Los Millennials son, por tanto, la futura generación de consumidores y usuarios, un mercado sustancial con nuevas características, necesidades y demandas que conviene conocer por las repercusiones y transformaciones que exigirá a las empresas" (Gutiérrez-Rubí, 2016, párr. 3).

Así, una etiqueta como la de Millennials podría ser parte de un discurso que apunta a legitimar ciertas formas de ser joven en las que se ocultan desigualdades sociales (por ejemplo, un joven nacido en los noventa que no logró concluir sus estudios en secundaria y que desde muy temprano debió enrolarse en espacios laborales informales ¿coincide con esa idea de joven- Millennial?), en favor de un discurso que, puesto de moda en ciertos escenarios, trata de dar cuenta dentro de determinadas circunstancias históricas que, paradójicamente, objetivan la subjetividad juvenil. 
En ese sentido, la totalidad de tales prácticas y discursos son también un vasto territorio que el analista puede explorar a condición de trazarse una ruta que le permita observar poco a poco, las diferentes características de un terreno muy explorado en los últimos años y por ende cartografiado de formas muy variadas.

La aspiración a la profundidad en relación a los discursos constructores de las subjetividades juveniles, queda, pues, lícitamente restringida a una ubicación transversal del tema. Aún más, si es plausible entender que en la construcción social de las subjetividades juveniles intervienen una amplia gama de discursos provenientes de fuentes tan variadas como el campo económico, el religioso, el artístico, el educativo entre otros, es además pertinente ubicar análisis localizados del tema alrededor de los discursos urdidos desde alguno de estos campos.

Emerge, de acuerdo con la tesis de que la juventud es una invención de la sociedad Moderna, la necesidad de reconocer cómo diferentes perspectivas enuncian y legislan sobre el ser social del joven.

En ese sentido, si se coincide con Feixa (2006) en que la juventud tal como se la entiende hoy es un producto original de la sociedad Moderna, esta derivación histórica supone dos aspectos claves:

-Una forma sociocultural de reconocimiento y participación social y política, dada a través de instituciones, organismos gubernamentales y no-gubernamentales o espacios creados por los mismos jóvenes.

-La inscripción dentro de la legislación nacional de los individuos que forman parte de este sector, de acuerdo con un particular reconocimiento de sus derechos, deberes y, por ende, su participación social.

Lo indicado en punto b conlleva reflexionar en torno a las leyes que enmarcaron y enmarcan hoy, la inserción juvenil en los espacios de participación social con base en un concepto de persona joven más o menos canónico.

\section{Los jóvenes como sujetos en la sociedad Moder- na: entre la adaptación y la resistencia al discurso adulto}


Reflexiones sobre la persona joven como sujeto social...

Muchos de los conceptos en torno al ser de lo juvenil suelen coincidir en al menos tres puntos básicos

-La juventud, en tanto que categoría donde se agrupa a diversos individuos, es tenida por síntesis de un subconjunto o sector social cuyo sentido está marcado por diferentes factores culturales que la caracterizan (su aparente transitividad, su pretendida disconformidad respecto del mundo adulto, su "vitalidad", entre otros).

-Se construye entonces como un sector generacional relativo dentro de la estructura total de la sociedad, cuyas cualidades destacan en distinción respecto a las de las otras generaciones: niñas y niños, adultos, ancianos.

-Para ella se estipulan ciertos roles en tanto que asignaciones o demandas reconocidas como propias de ese sector social.

Estos puntos básicos aparecerán urdidos alrededor de una plétora de discursos cuyo eje semántico suele ser una visión predominantemente adultocéntrica según la cual lo juvenil es entendido a partir de la mirada adulta, de su posición social, política y cultural respecto de la potencialidad adulta que las personas jóvenes llevan dentro, en el marco de una versión social de la teoría aristotélica de la potencia y el acto.

En efecto, como oportunamente señalara Revilla (2001), alrededor de los sujetos juveniles se urden discursos centrados en ideas como:

-La mitificación de lo juvenil, donde se entiende la condición de joven cual estado de plenitud.

-El hedonismo narcisista, que se enarbola como crítica de la exacerbada búsqueda del placer, el conformismo y la autoexaltación que pretendidamente caracterizarían a los jóvenes.

-La juventud como producto histórico-social, según la cual existiría una ontología juvenil típica de ciertos sujetos en determinada época histórica y determinadas condiciones sociales. 
-Los jóvenes como agentes de cambio, encargados de liderar grandes transformaciones sociales.

- La contestación juvenil, según la cual, el joven se contrapone al mundo adulto y sus diversos órdenes.

-Las subculturas juveniles (tribus, colectivos) como conjuntos diferenciados dentro de la sociedad.

-La transición a la adultez, donde el joven paulatinamente adquiere responsabilidades adultas.

-La juventud entendida como sector subordinado y discriminado respecto a una dominación adultocéntrica.

- La condición de joven en cuanto búsqueda de identidad dentro de un estadio de moratoria social y personal, desde donde se definiría la ulterior identidad individual y colectiva.

-El discurso de la diversidad juvenil, según el cual, ser joven se define por la pluralidad e incluso la contradicción entre diferentes mundos juveniles.

Para Revilla (2001) estos ejes discursivos presentan a la juventud como una población dependiente, subordinada y limitada en su acción respecto a los adultos, la cual, sin embargo, vive un momento de la vida altamente valorado cuyas limitaciones en apariencia se aligeran conforme los individuos acceden al mundo adulto. En esta misma línea, Duarte (2001) llama la atención sobre cierta tendencia dentro del discurso adultocéntrico a homogenizar la juventud en torno a consideraciones de transitoriedad, y a clasificarla según parámetros etarios, asignándole un conjunto de actitudes ante la vida que preparan al joven para la asunción de los roles adultos. Así, en el discurso adultocéntrico la juventud sería una especie de etapa de prueba.

El discurso adulto sería proclive, pues, a homogenizar diferentes experiencias individuales y colectivas bajo la categoría de la juventud, universalizando a través suyo ciertas características que estigmatizarían de forma negativa lo juvenil a partir de prejuicios y estereotipos o, en algunos casos, a idealizar lo juvenil desde una pretendida esencia "salvadora" del futuro. 
Reflexiones sobre la persona joven como sujeto social...

Quizá esta caracterización adultocéntrica ha redundado en una visión dicotómica sobre lo juvenil que en la sociedad Moderna ubica la forma de reconocimiento de los jóvenes a partir de dos referencias básicas:

-Lo juvenil como estadio de preparación para el mundo adulto y, por ende, como espacio para una adaptación sin sobresaltos al orden vigente

-O como periodo de oposición a las formas vigentes de hegemonía adulta.

Precisamente, tal como apunta Ulloa (2016) buena parte de los estudiosos y críticos de la modernidad presentan perspectivas sobre lo juvenil que se constituyen en tendencias epistémicas que ven a los sujetos jóvenes oscilando entre la adaptación y la resistencia social.

Por ejemplo, con pensadores como Adorno y Horkheimer se seguiría una visión pesimista sobre la adaptación social de los jóvenes. En relación al individuo de forma particular, Horkheimer (1973) señala que

Cuando hablamos del individuo como de entidad histórica nos referimos no sólo a la existencia espaciotemporal y sensoria de un miembro particular de la especie humana, sino también a la conciencia de su propia individualidad como ser humano consciente, proceso del que forma parte el conocimiento de su identidad. Esta apercepción de la identidad del yo no es experimentada por todas las personas con igual intensidad. Se encuentra más definida en los adultos que en los niños, a quienes todavía les falta aprender a hablar de sí mismos como 'yo', o sea la afirmación más elemental de identidad (p. 138).

En la línea de lo anotado por Ulloa (2016), la perspectiva de Horkheimer habla de un individuo anulado por una racionalidad que en la sociedad Moderna avanzada instrumentaliza la conciencia humana hasta derivar en la total enajenación del sujeto.

Así, el sujeto o, en este caso, la persona joven tendería a ser aherrojado a una lógica de reproducción de relaciones, vínculos y prácticas fundadas en esa instrumen- 
talización de la realidad, dentro de la cual el comportamiento se modela a imagen y semejanza de parámetros adultocéntricos que, por un lado, coartarían la espontaneidad juvenil, imponiendo cierta forma de ser y estar que se presenta a través una industria cultural encargada de reificar al sujeto.

Tal como apuntan Horkheimer y Adorno (1998) en el fragmento Marcados, los jóvenes, entonces, aunque recelaran de la adaptación acrítica del adulto al mundo, no podrían escapar de ser parte de esa adaptación que el orden social dominante difunde a través de tecnologías y estrategias de manipulación ideológica propias de la industria cultural, pues buena parte de las mercancías culturales tienen como público meta a las personas jóvenes.

Por contraposición, aunque sin desdeñar el tono crítico de la sociedad Moderna, Benjamin (1993) resalta el potencial revolucionario de la juventud, cuando efectúa un análisis sobre cómo los jóvenes de su época se erigieron como un grupo social de alto potencial subversivo, marchando a la vanguardia de la revolución cultural del siglo XX, en contra de los sectores adultos que, anclados en su conformismo y amparados bajo una falsamente valorada "experiencia", no hacían sino reproducir formas de vida insignificantes y monótonas que renunciaban y denunciaban los ideales propios de la juventud.

Benjamin (1993) confiaba plenamente en las capacidades de las personas jóvenes valorándolos como agentes de cambios que, en su criterio, podían llevar a la sociedad por la vía de nuevos órdenes culturales e históricos, inspirados por el ideal de la verdad como uno de los principios de vida, con lo que trastocarían instituciones como la religión, la educación, la política y: "[Las personas jóvenes] conocemos algo distinto, que ninguna experiencia nos ofrece, a saber: que existe la verdad aunque todo lo pensado hasta ahora sea un error; que la honradez debe mantenerse por mucho que hasta el día de hoy nadie haya sido honrado. Esta voluntad no nos la puede arrebatar ninguna experiencia [adulta]" (pp. 94-95)

Las posiciones de Benjamin por un lado, y de Horkheimer y Adorno por otro, representan en buena medida la ambivalente valoración de lo juvenil que se ha dado en la sociedad Moderna y que, como anota Ulloa (2016) se puede entender como un trasfondo ético desde el cual los discursos académicos construyen al sujeto joven y su agencia social entre la adaptación y la resistencia, 
Reflexiones sobre la persona joven como sujeto social...

pero que, además, enuncian aspectos de una tensión generacional que redunda, según Bourdieu (1990), en la ubicación de lo juvenil como una categoría social que permitiría la imposición de un cierto rol dentro del cual se pueden ubicar las trayectorias de vida de ciertos individuos.

Por ello Bourdieu (1990) advierte que la juventud no es algo dado: se configura en las luchas entre adultos y jóvenes y dentro de campos sociales en los que funcionan leyes específicas de envejecimiento, que sirven para ubicar dentro de un término como el de "juventud" a diferentes realidades juveniles a pesar de que pueda haber profundas diferencias entre ellas.

Se da de ese modo una permanente tensión entre los agentes jóvenes que aspiran a desplazar a los "viejos", sus antagonistas generacionales, y los agentes adultos que encarnan la sociedad de lo envejecido. Así, en el campo educativo se puede afirmar con Bourdieu (1990) que "estos conflictos se evitan mientras los viejos consiguen regular el ritmo del ascenso de los más jóvenes, regular las carreras y los planes de estudio, controlar la rapidez con que se hace la carrera [...]" (p. 173).

Se podría entender esta como una lucha entre individuos inscritos en el lugar de lo adulto-viejo y los inscritos dentro de lo juvenil, en un campo de juego en el que los opositores pugnan por el poder y los privilegios dentro de ese terreno.

Según las perspectivas de los autores antes mencionados, se puede identificar tres escenarios para el análisis del reconocimiento sociocultural de las personas jóvenes:

-El de la forma en que se tiende a reconocer la adaptación de los jóvenes dentro de un sistema social regido por los roles adultos.

-El de la forma en que se idealiza el potencial transformador de la juventud, de cara a la consolidación de un sistema social futuro.

-El de las formas específicas de tensión que se dan en las relaciones generacionales.

Con esos tres escenarios, conviene ahora indagar cómo se da el reconocimiento de los jóvenes en parte de la legislación costarricense. 


\section{La persona joven en la legislación costarricense}

Ni rebeldes ni adaptados. Ni contestatarios ni dominados. A primera vista pareciera que la legislación y la política costarricense sobre los jóvenes deja de lado cualquier posible contradicción social para entrar de lleno a proponer los derechos del ciudadano joven entendiendo a estos como "actores estratégicos" a los que se les debe ofrecer oportunidades y condiciones que garanticen sus derechos y su condición ciudadana.

De acuerdo con eso, la Política Pública de la Persona Joven se establece como

[...] el marco orientador de las políticas de juventud en Costa Rica, a partir de la Ley General de la Persona Joven [...]. $\mathrm{Su}$ objetivo es crear oportunidades y condiciones para garantizar el ejercicio de los derechos y de la ciudadanía de las personas jóvenes, el desarrollo de sus potencialidades y su aporte al desarrollo nacional (Consejo de la Persona Joven, 2011, párrs. 1-2).

Se trata, en ese sentido, de una herramienta fundamental que facilitaría la plena integración de las personas jóvenes dentro de diferentes espacios de participación social.

Por otra parte, la Ley General de la Persona Joven (2002) es el contexto jurídico en el que se desarrolla la Política. Por ello, el concepto de sujeto joven de esa ley es el modelo que marca las dimensiones del reconocimiento legal de lo juvenil, incluso entre la misma población joven.

De hecho, la consulta efectuada por Gutiérrez (2017) a personas adolescentes y jóvenes que estudian en secundaria o en el nivel universitario, evidencia que entre la población activa dentro del sistema educativo el conocimiento de esta legislación es alto (en promedio, cerca del $65 \%$ de las personas consultadas indicaron que conocían la Ley General de la Persona Joven), y se la estima como un instrumento clave para el efectivo ejercicio de los derechos y el desarrollo propios de esta población, aunque existan aún retos en torno a la reflexión de fondo sobre sus implicaciones y la articulación en el ámbito de los gobiernos locales. 
Reflexiones sobre la persona joven como sujeto social...

En el artículo 2 de la Ley General de la Persona Joven (2002) se reconoce como jóvenes a "Personas con edades comprendidas entre los doce y treinta y cinco años, llámense adolescentes, jóvenes o adultos jóvenes; lo anterior sin perjuicio de lo que dispongan otras leyes en beneficio de los niños y adolescentes" (p. 3).

Como se puede notar el reconocimiento parte de un marcador cronológico que se complementa con una serie de principios que podrían denominarse antropológicos, los cuales dicen más en detalle del reconocimiento del sujeto joven dentro de la legislación costarricense. Estos principios enunciados en el artículo 3 son (Ley General de la Persona Joven, 2002):

-El joven como actor social e individual de importancia estratégica para el desarrollo nacional.

-La particularidad y heterogeneidad de la juventud como grupo etario con características particulares (étnicas, culturales y de género).

-La integralidad de la persona joven, que comprende sus valores, creencias y tradiciones, juicio crítico, creatividad, educación, cultura, salud y su vocación laboral.

-Las condiciones sociales que procuren la igualdad de la persona joven.

- Y el reconocimiento de la juventud como un grupo social con necesidades propias, roles específicos y aportes por hacer a la sociedad, que son diferentes o complementan los de los de los adultos.

Ciertamente estos principios, que se pueden reconocer como antropológicos, guardan no pocas similitudes con la antropología liberal que sustenta buena parte de las declaraciones sobre derechos humanos que se han promulgado desde hace más de 300 años. Y ello obliga a reflexionar sobre las bases que los sustentan.

Por ejemplo, Hinkelammert (2005) propone una mirada crítica sobre la legislación moderna relativa a los derechos humanos, por considerarque en favor del capitalismo se ha invertido hasta llegar a ser instrumento de opresión de los derechos de pueblos que no caben dentro de un concepto de humanidad, basado en una noción de derechos esgrimida por Locke que "anula precisamente los derechos humanos de todos aquellos que ejercen resistencia frente a la sociedad burguesa y su lógica” (p. 94). 
No es posible afirmar a partir de la somera revisión aquí realizada, si efectivamente la legislación sobre juventud en Costa Rica, emanada de las bases antropológicas y de derechos propias de una sociedad enmarcada por la cultura burguesa occidental, corresponde a una histórica inversión de los derechos de sectores que no coinciden con un modelo juvenil ideal. Sin embargo, es oportuno reflexionar sobre las implicaciones sociales que hay tras el reconocimiento de la persona joven como individuo inserto en la estructura social, actuando desde un rol específico sin aparente menoscabo de su igualdad, que forma parte de un grupo social llamado a generar aportes para el desarrollo nacional y que complementan los logros alcanzados por los adultos.

En ese sentido se debe cuestionar de qué manera podrían aparecer ahí roles sociales legitimados y aceptados como válidos para las personas jóvenes desde la perspectiva adulta, avalados en tanto coadyuvan en una siempre problemática definición de "desarrollo social", que en el fondo propone al sujeto joven como agente social signado por la sociedad adultocéntrica.

En criterio de Zúñiga (2006), quien se basa en las perspectivas foucaultianas sobre el poder, el adultocentrismo se puede entender como una forma de tecnología del yo, esto es, una forma de saber que urdida en torno a la perspectiva adulta de lo social posibilita a los individuos jóvenes ciertas operaciones sobre sus cuerpos, pensamientos, conducta o "cualquier forma de ser" (p. 33). Se trata, pues, de una forma disciplinaria desde la cual los individuos reconocidos como jóvenes son sancionados y legalizados a la vez que se conforman ellos mismos a esta legislación.

Una opción de análisis que se puede desarrollar en futuras investigaciones sobre el tema, consistiría en indagar respecto de lo que en aquellos principios se denomina como "integralidad de la persona joven", para tratar de identificar si las creencias y tradiciones, el juicio crítico, la creatividad, la educación, la cultura, la salud y la vocación laboral que se enumeran ahí como rasgos de las personas jóvenes están influidos o son legitimados de acuerdo con las formas en que el saber adulto resuelve las tensiones generacionales (por ejemplo, ¿hasta dónde el juicio crítico de un joven es aceptado como tal y no como una muestra de sedición?, ¿qué reglas del mercado condicionan la "vocación laboral” de las personas jóvenes?). 
Reflexiones sobre la persona joven como sujeto social...

Por otro lado, en relación al reconocimiento de derechos, la Ley General de la Persona Joven (2002) en el artículo 4 indica que "La persona joven será sujeto de derechos; gozará de todos los inherentes a la persona humana garantizados en la Constitución Política de Costa Rica, en los instrumentos internacionales sobre derechos humanos o en la legislación especial sobre el tema" (p. 4).

De manera particular, la Ley General de la Persona Joven le garantizaría al sujeto joven costarricense, además, derechos especiales que se sintetizan en el siguiente cuadro, ya sea que estos se refieran a la acción individual o a la participación social.

\section{Cuadro 1. Distribución analítica de los derechos de la persona jo-} ven

\begin{tabular}{|c|c|}
\hline \multicolumn{2}{|c|}{ DERECHOS DE LA PERSONA JOVEN } \\
\hline Con referencia al individuo & $\begin{array}{l}\text {-Al desarrollo humano de manera in- } \\
\text { tegral } \\
\text {-A la salud, la prevención y el acceso a } \\
\text { servicios de salud que garanticen una } \\
\text { vida sana } \\
\text {-A la recreación, por medio de activi- } \\
\text { dades que promuevan el uso creativo } \\
\text { del tiempo libre, para que disfrute de } \\
\text { una vida sana y feliz } \\
\text {-A tener a su disposición, en igualdad } \\
\text { de oportunidades, el acceso al desarro- } \\
\text { llo científico y tecnológico } \\
\text {-A una educación equitativa y de carac- } \\
\text { terísticas similares en todos los niveles }\end{array}$ \\
\hline & $\begin{array}{l}\text {-A la atención integral e interinstitucio- } \\
\text { nal de las personas jóvenes, por parte } \\
\text { de las instituciones públicas y priva- } \\
\text { das, que garanticen el funcionamiento } \\
\text { adecuado de los programas y servicios } \\
\text { destinados a la persona joven }\end{array}$ \\
\hline
\end{tabular}




\begin{tabular}{|l|l|}
\hline Con referencia a la participación social & $\begin{array}{l}\text { A la cultura y la historia como expre- } \\
\text { siones de la identidad nacional y de } \\
\text { las correspondientes formas de sentir, } \\
\text { pensar y actuar, en forma individual o } \\
\text { en los distintos grupos sociales, cultu- } \\
\text { rales, políticos, económicos, étnicos, } \\
\text { entre otros } \\
\text {-A convivir en un ambiente sano y par- } \\
\text { ticipar de las acciones que contribuyan } \\
\text { a mejorar su calidad de vida } \\
- \text { Las personas jóvenes con discapaci- } \\
\text { dad a participar efectivamente en la } \\
\text { sociedad }\end{array}$ \\
\hline
\end{tabular}

Fuente: Elaboración propia en base al artículo 4 de la Ley General de la Persona Joven (2002).

Según lo anotado en el anterior cuadro, los derechos individuales se refieren principalmente a condiciones que permitirán al joven insertarse y participar adecuadamente dentro de la sociedad. Así, se propone el derecho al desarrollo integral, a la salud, a la educación, a la recreación y el acceso a la tecnología.

Si se observan con detenimiento, las bases de estos derechos individuales dejan de lado la particularidad juvenil, pues, así vistos, podrían enunciarse en favor de cualquier otro sector poblacional. En ese sentido se debe reflexionar si, la forma como se enuncian estos derechos, ¿supone una lógica homogeneizadora de derechos que asimila las características específicas de los sujetos jóvenes en favor de un orden social para el cual lo juvenil es despojado de cualquier posible especificidad generadora de tensiones respecto a la estructura hegemónica social?

Emerge así como tema para futuras indagaciones también, la problematización sobre cómo se inscribirían las tensiones intergeneracionales en estos derechos individuales, y de qué manera podrían ser moldura para la configuración de un ser joven socialmente reconocido en cuanto inscrito dentro de la dinámica del desarrollo económico neoliberal vigente, en donde un joven sano, educado y capaz de acceder a la tecnología, puede incorporarse de mejor manera a la estructura social. 
Reflexiones sobre la persona joven como sujeto social...

Esto último supone la ligazón entre los derechos individuales y los que se reconocen en referencia a la participación social. Estos son, en síntesis, derechos relativos a la participación en políticas sobre jóvenes, al trabajo, a la actividad cultural y a un ambiente sano.

En ese sentido, sería válido cuestionar si la promulgación de los derechos de un determinado sector poblacional evidencia la forma en que socialmente se procede, por un lado, a la entronización de los intereses de otro sector dominante sobre el que es sujeto de tales derechos, y por otra parte, a la posible neutralización legislativa de cualquier síntoma de aquella entronización.

Todo ello entendiendo que, según las perspectivas expuestas en este ensayo, es necesario reflexionar críticamente sobre cómo la Ley General de la Persona Joven (2002) en tanto producto social, podría ser amalgama de una cierta visión del sujeto joven con las expectativas y el reconocimiento consolidado desde la perspectiva adulta.

Pero también se debe revisar cómo la visión del sujeto joven esbozada en la legislación costarricense puede ser, además de un producto que cataliza cierta forma de reconocimiento social, vehículo para la posible construcción de identidades juveniles desde las cuales la participación promueva formas de inserción en la sociedad costarricense que integren las diferentes formas de vida concretas de las personas jóvenes, es decir, siguiendo a Filardo (2009), se trata de cuestionar la apertura de espacios para las subjetividades configuradas desde diversas temporalidades que dan sentido a la experiencia de lo vivido por las personas jóvenes, en sintonía con las circunstancias concretas (lugar socioeconómico, trayectoria educativa, entre otras) en las cuales arranca toda posible participación.

\section{A manera de conclusión}

Se ha llamado la atención sobre la idea de que la juventud, en tanto que categoría social emergente de la sociedad Moderna, supone la existencia de formas socioculturales de reconocimiento y participación social y política, rastreables en los marcos jurídicos de diferentes instituciones, organismos o espacios juveniles, al mismo tiempo que la inscripción legal de ciertos individuos que formarían parte de este sector, se realiza de acuerdo con una forma particular de reconocimiento 
de sus derechos y deberes.

De este modo, un acercamiento plausible, como el que apenas se ha bosquejado aquí, es el sondeo del problema del reconocimiento legal de los jóvenes dentro de la normativa institucional, de manera tal que se discuta la concepción de persona joven como sujeto social y político, esto es, como sujeto de derechos. Esto conlleva el interés por debatir en torno a las formas de reconocimiento oficial sobre los sujetos jóvenes en la actualidad.

Las reflexiones aquí presentadas parten de una idea base según la cual en las sociedades actuales, de acuerdo con el desarrollo social y político propio de la Modernidad, la concepción de las juventudes tiende a construirse a partir de cierto discurso adultocéntrico proclive a la homogenización de la juventud con base en atributos como la transitoriedad de la "etapa juvenil" y la clasificación de los individuos inscritos en ella según parámetros etarios, elementos ambos que, bajo la égida de una visión adulta de la sociedad, asigna un conjunto de actitudes ante la vida que, presuntamente naturales, predisponen al joven para asumir los futuros roles adultos. Así, la juventud aparece como una etapa de prueba en la vida del individuo.

Esta aproximación reflexiva, sucinta ciertamente, sugiere la posibilidad de analizar los contenidos de la Ley General de la Persona Joven en el sentido de cuestionar cualquier atisbo de tensión intergeneracional en la manera como se reconocen los derechos de la juventud costarricense, problematizando si estos funcionan como marco para el modelaje de un ser joven inscrito de lleno en la dinámica del desarrollo social vigente $\mathrm{y}$, por ende, valorado por su potencial de incorporación en la estructura socioeconómica predominante.

De ese modo, el cuestionamiento debe indagar si en la promulgación de los derechos de los jóvenes se evidencia cómo socialmente se entronizarían los intereses del sector adulto dominante a la vez que se borra, por así decir, cualquier posible evidencia de aquella entronización, siendo ese un problema que debe tomarse como una aproximación hipotética susceptible de contrastación en otros trabajos.

Un dilema epistemológico que debe profundizarse es si en la legislación revisada, se puede ubicar trazos de un discurso basado en una lógica de la potencia-acto que 
Reflexiones sobre la persona joven como sujeto social...

fungiría como metarrelato predominante en la mayor parte de los discursos sobre la juventud.

Se trataría de indagar si el reconocimiento de las personas jóvenes en el marco de la Ley General de la Persona Joven se enmarca en un modelo de raigambre aristotélica según el cual la persona joven es emulada con lo potencial y el adulto es tenido por acto humano. En efecto, ya se postule la observación de las condiciones relacionales juveniles, o se preste atención a la juventud como fase del desarrollo humano, o que sea tenida por una etapa de puesta a prueba socialmente valorada, o se quiera recuperar las diferentes formas de ser joven, es menester cuestionar si tras ese discurso operan formas adultocéntricas de valoración y concepción de lo juvenil.

Quizá la aparición de esa lógica de la potencia-acto social en la concepción de la juventud no debe sorprender, pues tanto los analistas cautelosos respecto de la juventud como los que sin reparo aceptan las bondades de este sector social, se ocupan en la dilucidación del ser del joven a partir de una constitución y caracterización que oscila entre lo potencial juvenil y lo actual adulto.

La posible pervivencia de esa lógica de la potencia-acto en la valoración del lugar juvenil dentro de la sociedad habla de una tarea pendiente: la investigación alrededor de las bases filosóficas de los discursos que fundamentan la legislación sobre juventud en Costa Rica.

\section{Referencias}

Benjamin, W. (1993). La metafísica de la juventud. Barcelona: Paidós.

Bourdieu, P. (1990). Sociología y cultura. México: Grijalbo.

Consejo de la Persona Joven. (2011). La política pública de la persona joven. Recuperado de http://cpj.go.cr/pol-tica-p-blica-de-la-persona-joven.html

Duarte, K. (2001). ¿Juventud o Juventudes? Acerca de cómo mirar y remirar a las juventudes de nuestro continente. En S. Donas, (comp.) Adolescencia y juventud en América Latina (pp. 57-74). Cartago: Libro Universitario Regional 
Feixa, C. (2006). Generación XX. Teorías sobre la juventud en la era contemporánea. Revista Latinoamericana de Ciencias Sociales, Niñez y Juventud. 4(2), julio-diciembre. Recuperado de http://www.redalyc.org/articulo. oa? $\mathrm{id}=77340202$

Filardo, V. (2009). Temporalidades juveniles. En El Uruguay desde la Sociología VI. (pp. 119-133). Montevideo: Facultad de Ciencias Sociales, Escuela de Sociología, Universidad de la República.

Gutiérrez, M. (2017). La Ley General de la Persona Joven y el ejercicio de los derechos de esta población. En T. Cordero, (comp.) Reflexiones desde la investigación socio-educativa en contextos de exclusión. (pp. 111-136). San José: INIE.

Gutiérrez-Rubí, A. (2016, 30 de mayo). 6 rasgos clave de los millennials, los nuevos consumidores. Forbes México. Recuperado de https://www.forbes. com.mx/6-rasgos-clave-de-los-millennials-los-nuevos-consumidores/

Hinkelammert, F. (2005). El sujeto y la ley. El retorno del sujeto reprimido. Heredia: Editorial Universidad Nacional.

Horkheimer, M. (1973). Crítica de la razón instrumental. Buenos Aires: Sur.

Horkheimer, M. y Adorno, T. (1998). Dialéctica de la ilustración. Fragmentos filosóficos. Madrid: Trotta.

Ley General de la Persona Joven. (2002). San José: Consejo Nacional de la Política Pública de la Persona Joven.

Política Pública de la persona Joven. (2004). San José: Consejo Nacional de la Política Pública de la Persona Joven.

Revilla, J. (2001) La construcción discursiva de la Juventud: lo general y lo particular. Papers. (63/64), 103-122. 
Reflexiones sobre la persona joven como sujeto social...

Souto, S. (2007). Juventud, teoría e historia: la formación de un sujeto social y de un objeto de análisis. Historia Actual Online. (13), invierno, 171-192. Recuperado de http://www.historia-actual.org/Publicaciones/index.php/haol/ article/view/208/196

Ulloa, G. (2016) Tendencias epistémicas sobre la categoría juventud. Una perspectiva foucaultiana. Revista de Ciencias Sociales. 29(38), enero-junio, 103-122.

Zúñiga, M. (2006). Cartografía de otros mundos posibles: el rock y el reggae costarricense según sus metáforas. Heredia: Editorial Universidad Nacional.

\section{¿Cómo citar este artículo?}

Ulloa Brenes, G. (Julio-diciembre, 2018). Reflexiones sobre la persona joven como sujeto social en la legislación costarricense Revista humanidades, 8(2), 1-21. doi: http://dx.doi.org/10.15517/h.v8i2.33335 